\title{
Studi Ekperimental Pengaruh Variasi Jenis Baterai (Alkaline, Lithium Ion, dan Nickel Metal Hydride) Terhadap Kecepatan, Gaya, dan Daya pada Konsep Kereta Elektromagnet
}

\author{
Desmas A. Patriawan*, Hery Irawan, Dhimas Hidayatullah, David Kurniawan \\ Jurusan Teknik Mesin, Fakultas Teknologi Industri, Institut Teknologi Adhi Tama, Surabaya, Indonesia \\ Email: *desmas@itats.ac.id
}

\begin{abstract}
Electromagnetic force can be used as a vehicle. Many studies have used the electromagnetic force to generate levitation on the train and the thrust on the train. This research tries to take advantage of the electromagnetic force to move the magnetized battery when it enters the copper trajectory. The speed measurement results obtained by the batteries (lithium-ion, $\mathrm{Ni-MH}$, and alkaline) are $1.16 \mathrm{~m} / \mathrm{s}, 0.77 \mathrm{~m} / \mathrm{s}$, and $0.85 \mathrm{~m} / \mathrm{s}$ respectively. However, when compared to the performance per watt, the Ni-MH battery has the best comparison value, while lithium ion has the lowest performance per watt.
\end{abstract}

Keywords: Battery types and power, Electromagnetic force, Train concept.

\begin{abstract}
Gaya elektromagnet bisa dimanfaatkan sebagai kendaraan. Banyak penelitian yang menggunakan gaya elektromagnet sebagai penghasil levitasi pada kereta dan gaya dorong pada kereta. Penelitian ini coba memanfaatkan gaya elektromagnet untuk menggerakan baterai yang diberi magnet saat memasuki lintasan tembaga. Hasil pengukuran kecepatan didapatkan baterai dengan lithium ion $1.16 \mathrm{~m} / \mathrm{s}$, Ni-MH $0.77 \mathrm{~m} / \mathrm{s}$ dan Alkaline $0.85 \mathrm{~m} / \mathrm{s}$. Namun hasil tersebut jika dibandingkan dengan performa per watt didapatkan baterai Ni-MH memiliki nilai perbandingan terbaik, sedangkan lithium ion memiliki performa per watt terendah.
\end{abstract}

Kata kunci: Gaya elektromagnet, Jenis baterai dan daya, Konsep kereta.

\section{Pendahuluan}

Pemanfaatan elektromagnet banyak sekali digunakan baik di bidang Industri maupun kesehatan [1], [2]. Elektromagnet juga bisa digunakan untuk menghasilkan gaya levitasi [3], [4], dimana gaya tersebut bisa dimanfaatkan untuk menggerakan benda tanpa menyentuh dan tidak menghasilkan gesekan. Elektromagnet juga bisa dimanfaatkan untuk pengembangan suspensi aktif pada kendaraan mobil [5], [6].

Tomohiro Keishi menjelaskan bahwa electromagnet masih banyak sekali kegunaanya, terutama jika digunakan untuk pengembangan produk berbasis elektrik [7]. Dalam bidang transportasi kereta berbasis maglev sudah mulai banyak diteliti dalam bentuk miniature maupun konsep desain, mulai dengan studi dan melakukan perhitungan untuk mendapatkan sistem kereta magnetic levitation (maglev) [8] dan menggunakan bahan superkonduktor untuk mendapatkan gaya elektromagnet yang besar tanpa arus yang besar [9].

Kereta dengan sistem maglev memiliki kelebihan tidak adanya gesekan antar rel dengan roda kereta. Secara teori kereta maglev dengan menghasilkan energy efisiensi lebih baik [10] dan menghasilkan kecepatan yang lebih tinggi dibandingkan dengan kereta konvensional (menggunakan rel dan roda) [11]. Pengembangan kereta maglev juga tidak mudah, karena perlu data yang akurat terhadap posisi kereta [12] dimana kereta ini punya potensi untuk memiliki kecepatan diatas 600 $\mathrm{km} / \mathrm{jam}$. Kecepatan yang tinggi pada kereta maglev akan memiliki permasalahan tersendiri terkait sistem dinamik kereta [13].

Penelitian terkait sistem maglev di Indonesia masih cukup jarang, sehingga pada penelitian ini coba membuat sistem elektromagnet sederhana dengan memanfaatkan gulungan tembaga, baterai dan 
magnet. Sistem ini memanfaatkan gaya elektromagnet yang dihasilkan dari magnet dan baterai terhadap tembaga sebagai lintasan kereta yang dibuat. Gaya yang dihasilkan untuk menghasilkan lontaran pada siste elektromagnet dapat dilihat dalam persamaan:

$F_{\text {em }}=B_{1} I_{2} l$

dengan $F_{\text {em }}$ adalah gaya electromagnet, $B_{1}$ adalah medan magnet, $I_{2}$ arus yang melewati konduktor, dan $l$ adalah panjang dari konduktor. Hubungan magnet dengan baterai mengasilkan medan magnet yang mempengaruhi arus $I_{2}$. Persamaan konduktor baterai, magnet dengan arus yang dihasilkan dapat dihitung dengan:

$B_{2}=\frac{2 k I_{2}}{r}$

dengan $B_{2}$ adalah circular magnetic field (CMF) dengan satuan tesla, $k=2 \times 10^{-7} N / I^{2}$ dan $r$ adalah radius dari tembaga. Persamaan (2) dapat diubah menjadi:

$I_{2}=\frac{B_{2} r}{2 k}$

Dengan mengganti $I_{2}$ yang didapatkan pada persamaan (3), maka persamaan gaya bisa didapatkan sebagai berikut:

$F=B_{1}\left(\frac{B_{2} r_{m}}{2 k}\right) l$

dengan $B_{1}$ medan magnet secara umum, $B_{2}$ adalah CMF yang dihasilkan dari arus $I_{2}, r_{m}$ adalah radius magnet dari CMF dan $l$ adalah panjang konduktor yang menghasilkan CMF $\left(B_{2}\right)$ yang berinteraksi dengan $B_{1}$, sehingga menghasilkan gaya lontar:

$F_{c m}=2 B_{1} B_{2} r_{m} l k^{-1}$

dengan $k^{-1}=5 \times 10^{6} N / T 2 . m$. Gambar gaya lontar baik secara repulsive (dorong) maupaun attractive (Tarik) dapat dilihat pada gambar 1.

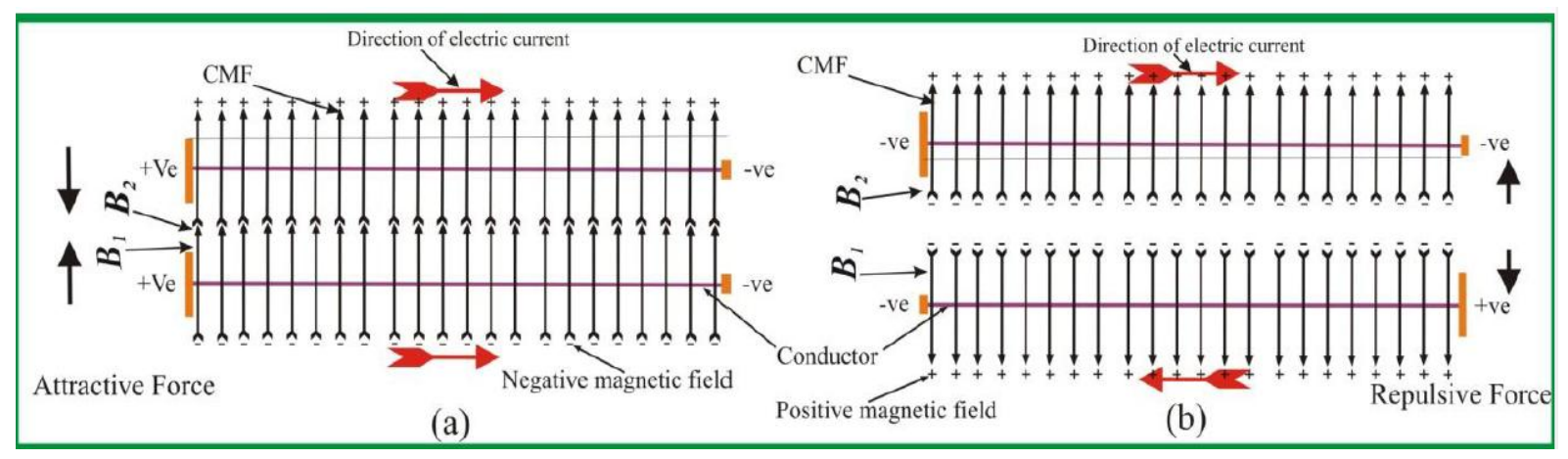

Gambar 1. (a) gaya lontar magnet attractive dan (b) gaya lontar magnet repulsive[14].

\section{Metode}

Tujuan dari penelitian ini adalah untuk melihat bagaimana pengaruh konsep kereta electromagnet terhadap variasi baterai terhadap kecepatan dan daya yang dihasilan. Langkah-langkah yang perlu dilakukan adalah dengan mencari variasi baterai dengan jenis berbeda dengan massa dan dimensi yang samakan. Jenis baterai yang digunakan adalah jenis Alkaline, nickel-metal hydride (Ni- 
MH) dan Lithium Ion. Dari sisi daya yang dihasilkan memang jenis lithium ion memiliki daya yang lebih besar dari 2 jenis baterai lainya [15], [16]. Selain itu data spesifikasi lithium ion dengan tegangan $3.7 \mathrm{~V}$ dan kapasitas $3000 \mathrm{mAh}$, Ni-MH dengan $1.2 \mathrm{~V}$ dan kapasitas $950 \mathrm{mAH}$ dan alkaline dengan 1.5 $\mathrm{V}$ dan $1000 \mathrm{mAh}$ juga menunjukan bahwa jenis lithium ion punya tegangan dan kapasitas paling besar. Namun dari penelitian ini coba dilihat berapa selisih performa bisa dijadikan perbandingkan yang menarik.

Ketiga baterai tersebut dipasangkan dengan magnet jenis neodymium jenis N52 dengan diameter $15 \mathrm{~mm}$, tebal $2 \mathrm{~mm}$ sebanyak 10 magnet. Medan magnet yang dihasilkan dari jenis magnet ini adalah 1.43 Tesla. Pemasangan magnet dengan baterai dapat dilihat pada gambar 2. Pemasangan magnet dengan cara 5 magnet di kutub positif dan 5 magnet pada kutub negatif.

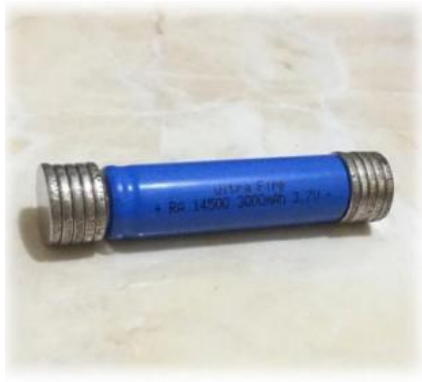

(a)

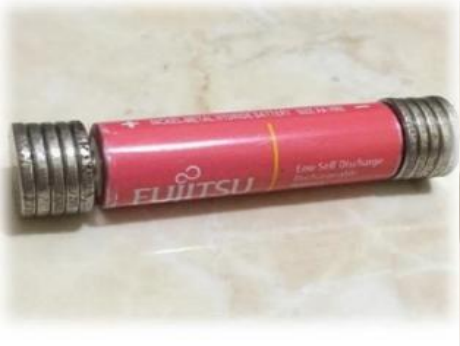

(b)

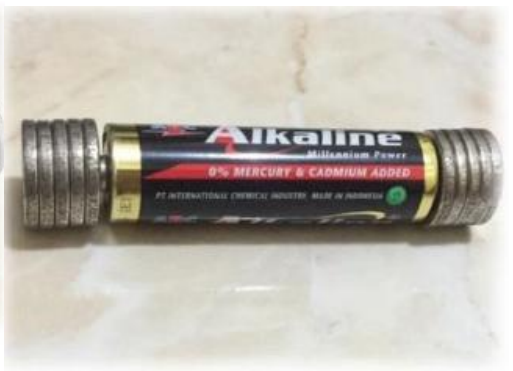

(c)

Gambar 2. (a) Lithium Ion dengan Magnet, (b) Ni-MH dengan magnet dan (c) Alkaline dengan magnet.

Lintasan yang digunakan adalah kawat tembaga dengan diameter $1.5 \mathrm{~mm}$. Kawat tembaga tersebut dililit dengan rapat sampai memiliki lintasaan sepanjang 1 meter. Lintasan kawat tembaga tersebut juga diberikan tegangan DC sebesar $5 \mathrm{~V}$. Lintasan yang dibuat untuk penelitian ini dapat dilihat pada gambar 3 .

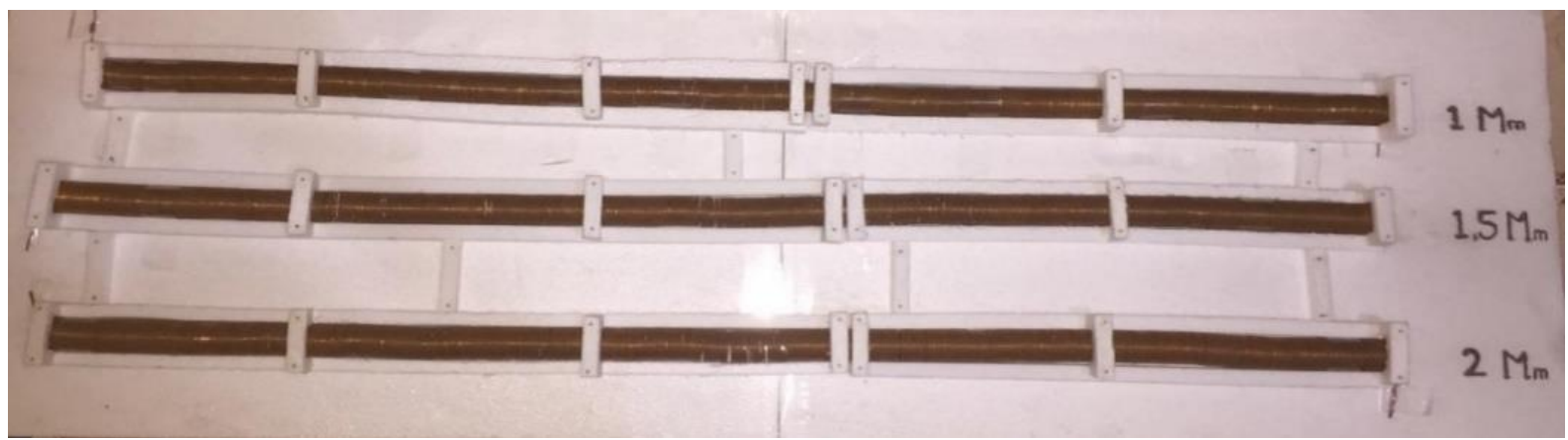

Gambar 3. Lintasan pada konsep kereta elektromagnet.

Pengujian dilakukan dengan mengukur kecepatan dari baterai yang diberi magnet saat melalui lintasan sebesar 1 meter. Pengukuran waktu tempuh jenis baterai terhadap lintasan menggunakan stopwatch. Pengujian dilakukan sebanyak 5 kali dengan pada setiap jenis magnet. Pengujian dilakukan dengan kondisi magnet baru atau pada lithium ion dan Ni-MH di isi ulang sampai penuh. Bentuk alat uji dan bagian-bagiannya dapat dilihat pada gambar 4 . 


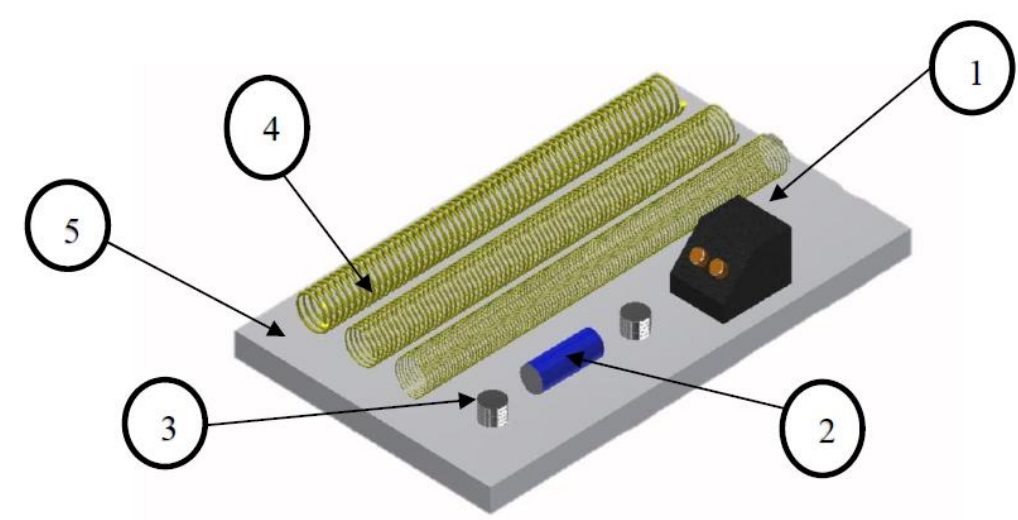

Gambar 4. Alat uji konsep kereta elektromagnet.

Bagian dari alat-alat ini adalah:

1. Power supply digunakan untuk menambahkan tegangan pada lintasan.

2. Baterai yang digunakan pada penelitian ini

3. Magnet jenis N52 sejumlah 10 magnet.

4. Lintasan yang terbuat dari gulungan tembaga.

5. Base atau penampang dari alat uji yang terbuat dari bahan yang tidak menghantarkan listrik dan magnet.

\section{Hasil dan Pembahasan}

Hasil pengukuran yang dilakukan dengan stopwatch dengan mengukur waktu yang diperlukan baterai dan magnet yang menempuh panjang lintasan 1 meter. Hasil dari pengukuran dapat dilihat pada tabel 1. Hasil tersebut memperlihatkan bahwa waktu yang ditempuh oleh lithium ion paling pendek dengan waktu tercepat adalah 0.86 detik dan terlama 0.99 detik. Dari tabel juga dapat dilihat adanya proses perlambatan waktu tempuh, hal ini bisa terjadi karena daya yang ada baterai juga mengalami pengurangan saat dilakukan pengujian berkali-kali.

Tabel 1. Data hasil pengukuran lama waktu magnet dan baterai dengan panjang lintasan 1 meter.

\begin{tabular}{cccc}
\hline No & Variasi baterai & Panjang Lintasan $(\boldsymbol{m})$ & $\begin{array}{c}\text { Hasil pengukuran } \\
\text { (detik) }\end{array}$ \\
\hline 1 & Lithium ion & 1 & 0.86 \\
& & & 0.88 \\
& & 0.91 \\
& & & 0.93 \\
& & 1 & 0.99 \\
\hline 2 & Ni-MH & & 1.30 \\
& & & 1.38 \\
& & & 1.45 \\
& & 1.51 \\
& & & 1.53 \\
& & & 1.18 \\
& & & 1.20 \\
& & & 1.25 \\
& & & 1.31 \\
& & & 1.32 \\
\hline
\end{tabular}

Hasil yang didapatkan pada tabel kemudian dihitung kecepatan dengan cara jarak tempuh dibagi dengan waktu yang diperlukan. Hasil perhitungan tersebut menghasilkan kecepetan yang dapat dilihat pada Gambar 5. 


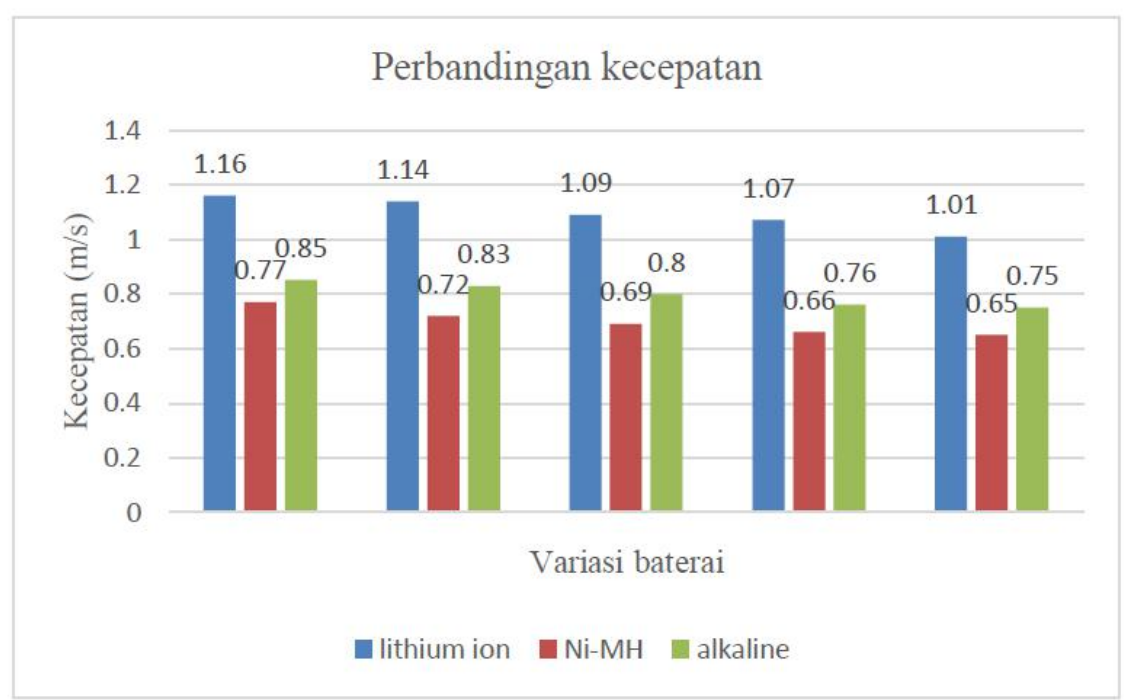

Gambar 5. Hasil perhitungan kecepatan variasi baterai terhadap konsep kereta elektromagnet.

Hasil yang dilihat pada gambar 5 memperlihatkan bahwa baterai dengan jenis lithium ion memiliki kecepatan yang tertinggi dengan $1.16 \mathrm{~m} / \mathrm{s}$ sedangakan jenis baterai Ni-MH justru mendapatkan kecepatan terendah dengan $0.77 \mathrm{~m} / \mathrm{s}$. Hasil tersebut sudah dapat diidentifikasikan dengan data spesifikasi pada jenis baterai dimana baterai jenis lithium ion memiliki tegangan dan kapasitas baterai terbesar dan baterai jenis Ni-MH memiliki tegangan dan kapasitas terendah.

Pembahasan berikutnya adalah dengan membandingkan performa dari ketiga jenis baterai tersebut. Jika baterai jenis lithium ion kita di $100 \%$ performa maka hasil perbandingan performa dapat dilihat pada gambar 6 .

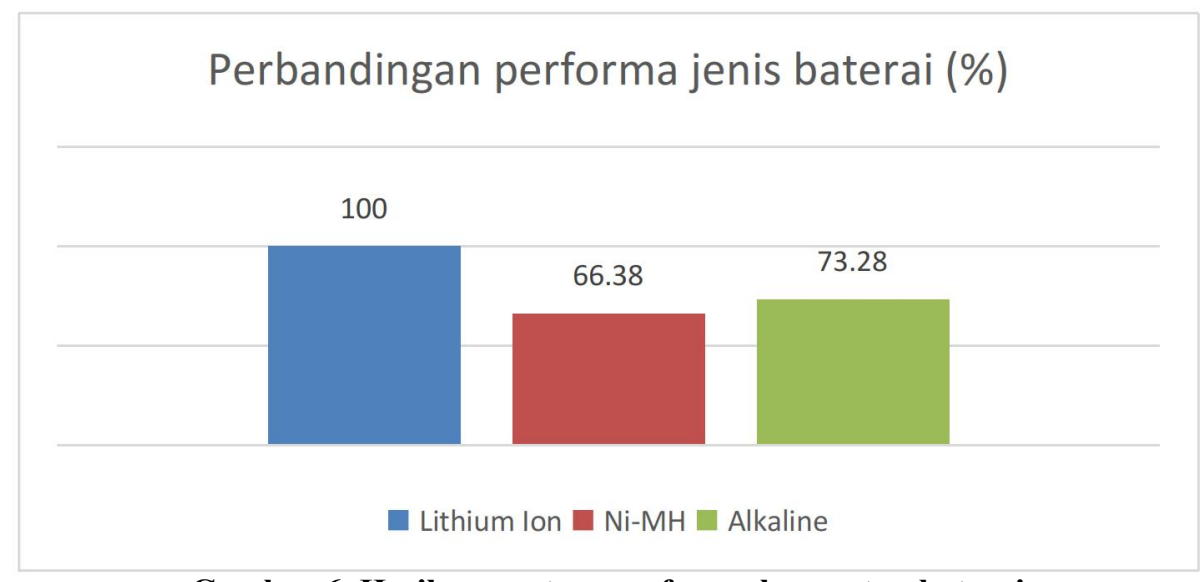

Gambar 6. Hasil persentase performa kecepatan baterai.

Hasil tersebut selisih performa antara lithium ion dengan Ni-MH sekitar 33,62 \% dan 22,72 \% dengan Alkaline. Hasil selisih performa cukup besar namun hasil performa tersebut dibandingkan juga dengan daya dari masing-masing baterai.

Daya yang dihasilkan lithium ion sebesar 11,1 Watt, daya yang dihasilkan Ni-MH 1,14 Watt dan Alkaline 1,5 Watt. Dari daya tersebut kemudian dibagi pada perfoma dari tiap baterai. Hasil perbandingan daya dan performa dapat dilihat pada Gambar 7. 


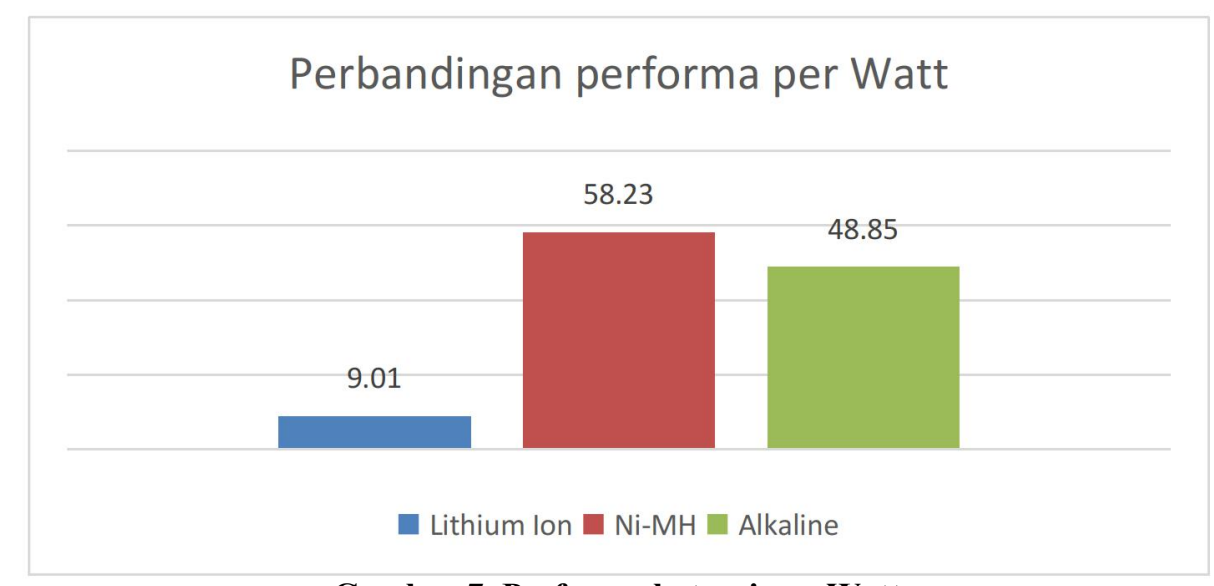

Gambar 7. Performa baterai per Watt.

Hasil dari performa per Watt justu didapatkan baterai Ni-MH dimana Watt yang dihasilkan kecil namun memiliki performa hanya selisi 33,62 \%. Hasil ini menarik karena sekalipun menghasilkan daya yang lebih besar pada baterai lithium ion namun selisihnya tidak terlalu besar jika dibandingkan performa dari baterai Ni-MH dan Alkaline.

\section{Kesimpulan}

Pengujian kecepatan pada konsep kereta elektromagnet dengan perbandingan baterai jenis baterai menghasilkan baterai dengan lithium ion memiliki kecepatan $1,16 \mathrm{~m} / \mathrm{s}$, Ni-MH 0,77 m/s, dan Alkaline $0,85 \mathrm{~m} / \mathrm{s}$. Hasil tersebut sesuai dengan daya yang dihasilkan pada baterai sehingga gaya electromagnet juga semakin besar. Namun bagian yang menarik adalah perbandingan daya dengan performa justru baterai dengan lithium ion lebih rendah nilainya jika dibandingkan dengan baterai Ni-MH dan Alkaline

\section{Referensi}

[1] D. H. Staelin, "Electromagnetics and Applications," p. 443.

[2] H. C. Lai and N. P. Singh, "Medical applications of electromagnetic fields," IOP Conf. Ser. Earth Environ. Sci., vol. 10, p. 012006, Apr. 2010, doi: 10.1088/1755-1315/10/1/012006.

[3] D. A. Patriawan, B. Pramujati, and H. Nurhadi, "Preliminary Study on Magnetic Levitation Modeling Using PID Control," Appl. Mech. Mater., vol. 493, pp. 517-522, Jan. 2014, doi: 10.4028/www.scientific.net/AMM.493.517.

[4] B. Pramujati, H. Nurhadi, and D. A. Patriawan, "A Study on the Effect of an Attractive and a Repulsive Forces with Feedback Control on a Magnetic Levitation System," vol. 6, no. 6, p. 5, 2015.

[5] D. A. Patriawan, H. Irawan, A. Noerpamoengkas, B. Setyono, and A. Y. Ismail, "Definition, criteria and approaches in designing suspension system with active controls," IOP Conf. Ser. Mater. Sci. Eng., vol. 1010, p. 012006, Jan. 2021, doi: 10.1088/1757-899X/1010/1/012006.

[6] B. L. J. Gysen, J. J. H. Paulides, J. L. G. Janssen, and E. A. Lomonova, "Active Electromagnetic Suspension System for Improved Vehicle Dynamics," IEEE Trans. Veh. Technol., vol. 59, no. 3, pp. 1156-1163, Mar. 2010, doi: 10.1109/TVT.2009.2038706.

[7] T. Keishi, "Electromagnetic Field Analysis and Its Applications to Product Development," p. 9.

[8] R. Ahmed, Y. L. Jun, M. F. Azhar, and N. U. R. Junejo, "Comprehensive Study and Review on Maglev Train System," Appl. Mech. Mater., vol. 615, pp. 347-351, Aug. 2014, doi: 10.4028/www.scientific.net/AMM.615.347.

[9] K. Sawada, "1. Superconducting Maglev," p. 10, 2000.

[10] Z. Qadir, A. Munir, T. Ashfaq, H. S. Munawar, M. A. Khan, and K. Le, "A prototype of an energy-efficient MAGLEV train: A step towards cleaner train transport," Clean. Eng. Technol., vol. 4, p. 100217, Oct. 2021, doi: 10.1016/j.clet.2021.100217. 
[11] C. Palmer, "Engineered to Go Fast, Maglev Trains Inch Forward," Engineering, p. S2095809921002289, Jun. 2021, doi: 10.1016/j.eng.2021.06.001.

[12] Y. He, J. Wu, G. Xie, X. Hong, and Y. Zhang, "Data-driven relative position detection technology for high-speed maglev train," Measurement, vol. 180, p. 109468, Aug. 2021, doi: 10.1016/j.measurement.2021.109468.

[13] F. Guo, S. Wu, J. Liu, Z. Wu, S. Fu, and S. Ding, "A time-domain stepwise fatigue assessment to bridge small-scale fracture mechanics with large-scale system dynamics for high-speed maglev lightweight bogies," Eng. Fract. Mech., vol. 248, p. 107711, May 2021, doi: 10.1016/j.engfracmech.2021.107711.

[14] M. E. Yousif, "The Unified Force of Nature: 1-The Electric \& Magnetic Forces," p. 18.

[15] C. Iclodean, B. Varga, N. Burnete, D. Cimerdean, and B. Jurchiş, "Comparison of Different Battery Types for Electric Vehicles," IOP Conf. Ser. Mater. Sci. Eng., vol. 252, p. 012058, Oct. 2017, doi: 10.1088/1757-899X/252/1/012058.

[16] R. Borah, F. R. Hughson, J. Johnston, and T. Nann, "On battery materials and methods," Mater. Today Adv., vol. 6, p. 100046, Jun. 2020, doi: 10.1016/j.mtadv.2019.100046. 
72 Jurnal Teknologi dan Manajemen, Vol 2, No 2, Agustus 2021: 65-72

- Halaman ini sengaja dikosongkan - 